Article

\title{
Social Media Providing an International Virtual Elective Experience for Student Nurses
}

\author{
Paula M. Procter ${ }^{1, *}$, Juliana J. Brixey ${ }^{2}$, Fern Todhunter ${ }^{3}$ and Michelle L. L. Honey ${ }^{4}$ \\ 1 Department of Nursing and Midwifery, Sheffield Hallam University, Sheffield S1 1WB, UK \\ 2 University of Texas Health Science Center at Houston, Houston, TX 77030, USA; \\ Juliana.J.Brixey@uth.tmc.edu \\ 3 Faculty of Medicine and Health Sciences, University of Nottingham, Nottingham NG7 2RD, UK; \\ Fern.Todhunter@nottingham.ac.uk \\ 4 Senior Lecturer, School of Nursing, The University of Auckland, Auckland 1142, New Zealand; \\ m.honey@auckland.ac.nz \\ * Correspondence: p.procter@shu.ac.uk; Tel.: +44-114-225-5392
}

Academic Editors: Elizabeth Cummings and Carey Mather

Received: 13 March 2017; Accepted: 7 April 2017; Published: 10 April 2017

\begin{abstract}
The advances in social media offer many opportunities for developing understanding of different countries and cultures without any implications of travel. Nursing has a global presence and yet it appears as though students have little knowledge of the health and social care needs and provision outside their local environment. Our collaboration across three countries, New Zealand, United Kingdom, and the United States of America, brought the two themes together with the aim of senior student nurses having a communication channel to explore public health issues in each country. Using a closed Facebook ${ }^{\mathrm{TM}}$ page, third year undergraduate adult nursing students were invited to take part in a three month pilot study to test the feasibility of virtual collaboration through exchanging public health issues. Here we report upon the collaboration, operation of the social media, and main findings of the study. Three core areas will be reported upon, these being the student's views of using social media for learning about international perspectives of health, seeing nursing as a global profession and recommendations for future development of this positively reviewed learning technique. To conclude consideration will be given to further development of this work by the collaborative team expanding the countries involved.
\end{abstract}

Keywords: social media; nurse education; international public health; global information exchange

\section{Background}

Exchange activities have been found to facilitate excellent opportunities for intercultural learning. Such scholarly collaborations are usually direct and often abroad. The outcomes for student exchange are broadly related to global appreciation, cross-cultural knowledge and the skills required in a diverse nursing workplace. These attributes are important for registered nurses, given the cultural dexterity required in the delivery of health and social care [1]. Nursing has a global presence and yet it appears as though students have little knowledge of the health and social care needs and provision outside their local environment [2]. This paper reports an exploratory study that evaluated if a virtual exchange using one application within the social media genre namely Facebook ${ }^{\mathrm{TM}}$, which was designed to help prepare nurses for their professional career in a global environment where collaboration will be valuable to resolve public and population health issues, is effective and acceptable to nursing students.

The research team were particularly interested to determine if student nurses can use this form of social media to enhance their understanding of health and social care away from their home base. Social media was also assessed for its suitability for students to exchange ideas about different ways 
health and social care is provided which might be transferable to their own care delivery context. For the student participants to fully engage and share ideas, privacy and security must be maintained. This was accomplished through the use of a closed group Facebook ${ }^{\mathrm{TM}}$ page.

Using social media such as Facebook ${ }^{\mathrm{TM}}$ in education requires an educational framework that acknowledges the use of evolving technologies, that students are encouraged to form networks to exchanges ideas and learn from each other, and values the timeliness of the information. Social media opens opportunities for students to exchange ideas both synchronously and asynchronously and extends beyond the face to face classroom [3]. The research team used a connectivist framework for the study as this appeared to be the most appropriate for the widest opportunity for content development by the students. In 2004 Siemens proposed a new learning theory of Connectivism derived from chaos, network, and complexity and self-organizing theories. Downes [4] commented on connectivism "as a pedagogy that (a) seeks to describe successful networks (as identified by their properties, which has been characterized as diversity, autonomy, openness, and connectivity); and (b) seeks to describe the practices that lead to such networks, both in the individual and in society (which has been characterized as modelling and demonstration (on the part of the teacher) and practice and reflection (on the part of the learner))". Downes [5] further asserts that connectivism hypothesizes that "knowledge is distributed across a network of connections, and therefore learning consists of the ability to construct and transvers those networks."

Connectivism is grounded in the following eight assumptions [6]:

- Learning and knowledge rests in diversity of opinions

- Learning is a process of connecting specialized nodes or information sources

- Learning may reside in non-human appliances

- Capacity to know is more critical than what is currently known

- Nurturing and maintaining connections is needed to facilitate continual learning

- Ability to see connections between fields, ideas, and concepts is a core skill

- Currency (accurate, up-to-date knowledge) is the intent all connectivist learning activities

- Decision-making is a learning process

The framework for this study uses the assumptions of diversity of opinions, connection of nodes, nurturing and maintaining connections, and to identify interdisciplinary nature of healthcare as a core skill, which seemed a robust exploratory structure upon which to build the research.

\section{Method}

This exploratory study aimed to describe the exchange and collaboration amongst students from four sites in three countries. Due to the innovative approach using international collaboration and Facebook $^{\mathrm{TM}}$ the exploratory study ran for three months from March to May 2016. The objectives of the study were to:

1. Assess the metrics and analytics of the Facebook ${ }^{\mathrm{TM}}$ page for timing, number of entries, patterns of usage

2. Analyze the entries to gauge the students' understanding of their own and international population health needs and to

3. Evaluate student's perceptions of engaging in this virtual exchange.

The study aimed to recruit 10 nursing students from each of four sites (United States, New Zealand and 20 students from the United Kingdom (10 from the University of Nottingham, and 10 from Sheffield Hallam University). Participation was voluntary and no grades or assessments were associated with this study. Students who agreed to participate were invited to join a closed Facebook ${ }^{\mathrm{TM}}$ page where they could upload postings, read other postings and join individual chats at times convenient to them. Here they were directed to discuss nursing and nursing education from their respective countries and to 
explore the similarities and differences of public/population health across the three countries involved. Faculty involvement on the Facebook ${ }^{\mathrm{TM}}$ page was minimal and mostly focused on encouraging students to use a diverse range of media and sources of information to gain a comprehensive appreciation of different population needs and outcomes. Each academic site gained human subjects ethical approval for the study.

Quantitative methods were used to analyse student demographics and using Facebook ${ }^{\mathrm{TM}}$ analytics provided data of patterns of Facebook ${ }^{\mathrm{TM}}$ usage. Content analysis was used to determine themes and trends in the postings to determine the student's understanding of local and international public and population health needs. Additionally, student feedback was sought about their perceptions of engaging in this virtual exchange. Facebook ${ }^{\mathrm{TM}}$ was the selected social media of choice as it supports free access, ease of use and is a commonly used social media site thought to be likely to present good conditions to facilitate academic activity on a global scale with different groups of learners. Research into social media use is an emerging discipline and our paper adds to the growing interest in the creation and exchange of content.

\section{Results}

Students were recruited from the University of Auckland, Sheffield Hallam University and the University of Nottingham. Due to unforeseen circumstances no students were recruited from the University of Texas Health Science Center. There were 21 students involved along with two academic members of staff who were not part of the research team and as such were able to act independently.

The students were all completing the third year of their undergraduate nursing course. Of the 21 students who participated two were male and the remainder female (19). Over the three months of the pilot 60 discussion topics were initiated, 18 by the research team and the remainder (42) started independently by the students. All but two students initiated a topic with the range of topics individually initiated ranging from zero to seven; all but three students not adding to/commenting upon a topic with a range of added comments to each topic being zero to 10 . The total number of entries was 147.

Along with the visible activity within the closed Facebook ${ }^{\mathrm{TM}}$ page data were collected on the 'Likes' and 'Seen By' metrics. In all there were 26 individuals with access to the page, 21 students, 2 independent academics and the 4 collaborative researchers. The results below are given by month (Table 1):

Table 1. 'Like' and 'Seen By' Results.

\begin{tabular}{ccc}
\hline Month & Like (Range) & Seen By (Range) \\
\hline March & $0-8$ & 26 \\
April & $0-3$ & $18-26$ \\
May & $1-6$ & $17-23$ \\
\hline
\end{tabular}

The high level of 'Seen By' results needs further investigation and will be included in our future work as it appears as though students retained an interest in the postings throughout the three months they did not always feel it was necessary to add a comment.

\section{Student Perceptions}

Feedback from students was sought and quotes indicate their words. Social media was considered "a good way to make contact with students from other universities". Four aspects were evident from the student feedback: Social, learning about international perspectives of health, seeing nursing as one profession, and the students also had recommendations on how to improve the virtual electives for future students. 


\subsection{Social}

Students described "enjoying the social aspects" of the virtual elective and "being part of a group". Whilst acknowledging that it was "good to interact with other student nurses worldwide", disappointment that they "couldn't all meet in person and have these conversations" was also expressed.

\subsection{Learning about International Perspectives of Health}

The virtual elective enabled students to "gain understanding of differing healthcare requirements worldwide". They described being "more aware of international topics that involves nursing", and specifically "problems like the Zika virus" were seen as "a global health issue". Overall students considered it "interesting to view opinions on public health matters", and the virtual elective gave them a broader perspective of health issues.

\subsection{Seeing Nursing as One Profession}

"It was interesting to see how one profession can be done in many different ways" exemplifies this aspect from student feedback. Students described liking "connecting with other nurses from around the world and comparing similarities and differences" and having the opportunity to "learn about the culture of other nurses". Students noted that the "core concepts of nursing across the countries are exactly the same" and the appreciated being able to "learn about the different nursing education systems". The benefits of connecting to other student nurses were understood, and explained by one student who said: "This would be great when we're qualified in order to share ideas and experiences as newly qualified nurses".

\subsection{Student Recommendations}

Although the feedback was predominantly positive, suggestions to improve the virtual elective experience were also shared and included: "Making sure everyone contributes", including "some form of icebreaker" so they could get to know each other initially, having "a weekly topic" for discussion, and to "broaden the topics for discussion beyond public health". Additionally, students recommended having "more nationalities" and "participants from countries other than just from the western world". These ideas are considered further later in this paper.

\section{Themes and Trends}

The students posted comments about a broad range of public health issues. These can be organised as: Professional understanding based on experiential learning from placements and academic knowledge based on classroom activity and course requirements, personal issues located in a public health context and current issues capturing global attention at the time of the project. Students also sought information about professional opportunities based on course and curriculum structures. Initial posts reflected experiential learning in the clinical area. The posts were written using a combination of academic and conversational styles. "I'm interested in emergency care and critical care. Keen to hear about everyone else's experiences." "I've spent a couple of weeks at placement for both and loved it." "I have an interest in dementia care." "Snap! You and I are the dementia queens. I love this area and find mega interesting." The running commentary about personal placement experiences sparked further points and questions about Dementia. "Dementia is a subject that intrigues me. How do your countries deal with it and what provisions are put in place?" The responses included a reference to the film 'About Alice.' "It shows the processes people go through when diagnosed with Alzheimers."

The timely coincidence of the Olympics in South America triggered comments on Zika Virus and the public health implications for the domicile population and the Games' participants. "Have there been any cases of Zika reported in the UK?" One student identified the paradox of travel to Brazil 
and the consequence. "Specifically as a woman at child-bearing age and its unknown effects for the future. Is it worth the risk?" "Zika virus is spread by mosquitoes. For most people it is a very mild infection and isn't harmful. It is dangerous in pregnant women" Significantly none of the group had experienced working with patients with the Zika Virus, but the posts reflected biological knowledge and social consequences.

These posts were about health elsewhere and students' readiness to consider how populations deal with what is happening in their own location. Likewise the posts about non-contact rugby tackling demonstrated secondary or vicarious understanding of issues students knew about, but not through direct experience. For example, the discussion about non-contact rugby tackling was an exploration of the relationship between population health and public health. The non-contact rugby tackle in UK schools was a topic of interest for UK and New Zealand students as rugby is a national sport. Sport is an excellent public health promoter because of its global common denominators. These posts also showed students' knowledge of the links between contact sports and dementia. "In New Zealand there is currently talk about ex-rugby players with dementia." "Yeh ... they are also linking boxers with a form of dementia."

Interestingly, the personal context of public health gave students a glimpse into each other's private lives. In sharing aspects of their domestic circumstances and routine, they revealed similar challenges occurring across the globe. Issues with access to car park space in practice areas and the stress this causes, do not reflect the high profile of those issues which traditionally dominate the public health agenda; for example, smoking, exercise and diet. "How do you go on for parking in your countries at your place of work? We have to pay and then struggle to park." "Shuttles between offsite car parking and the hospital don't necessarily go at shift times." "Even as a student work related stress worries me." This discussion shows students appreciation of the changing contours of public health and how they both deliver and receive the outcomes from strategic intentions.

In a social media environment such as Facebook ${ }^{\mathrm{TM}}$ exchanges about study were always going to be inevitable and were actively encouraged. One example was the completion of a portfolio of practice-based evidence and the anxiety this generated. "I' $m$ just interested to note whether students outside UK complete a paper portfolio as well as e-portfolio?" "It's like a minefield completing and compiling evidence that requires merging into both versions." "Just online here in NZ." These kinds of posts offer a taste of direct real time connections on a global scale. Comparisons and contrasts in course structure and organisation of studies were an opportunity to find what it is like to live and learn in a different area, but working towards the same goals. An emerging theme was plans for future work activity. "I can't believe how fast the first two years have gone. I'm contemplating where I would like to work." "The people from NZ what degree are you doing? You say you enjoyed your adult, paediatric and mental health placements." "We are technically comprehensively trained and can work anywhere when we graduate." "That sounds good." "The UK nursing course used to be set out like this."

Globally, nurses make a significant contribution towards maintaining and promoting public health. The broad and global application of public health may seem overwhelming to the individual undergraduate learner. From the outset of their studies, student nurses are introduced to policy determinants, a diverse range of subjects and how public health programmes are organised, received and acted on. Social media has accelerated these processes and presents opportunities for students to work in groups exploring some aspects of global public health; commencing with what they know already and what they have learnt in the course of their studies. The themes reflect public health as an ever-present influence and our paper shows students' abilities to think critically about their personal and professional experiences.

\section{Discussion}

Students from four Universities were invited to participate in a Closed Facebook ${ }^{\mathrm{TM}}$ activity. The unique selling features of ring-fencing were the researchers' duty of care to protect the group, 
generating a trustful environment and addressing the common challenge of determining the location of the user [7]. This was evidenced by the open sharing of ideas by the students. The advances in technology and social media in particular allow us all to be part of the 'connected' world. This exploratory project offered an opportunity to explore the interaction between students and the health and social care world around them using a media that is regularly used in a non-professional context. In education the movement towards a belief that we use connections to respond to our questions rather than try to store huge quantities of knowledge individually requires an enquiring mind and a recognition that we need to seek new knowledge. The students in this exploratory study did demonstrate an interest in looking beyond their own experiences and the themes emerging have shown those areas that were or were not meaningful to the students who took part.

Initial posts reflected experiential learning in the clinical area. A running commentary about skin integrity and tissue viability initially focused on the older person population. In moving the dialogue to generic skin protection and epidemiological consequences, the group recognized and chatted about nurses' health education roles in risk reducing behaviours [8]. The posts reflect the value of promoting public health messages in non-health arenas and providing a global picture reflects gaps in quality and type of provision [9].

The discussion also focused on sharing knowledge, for example, about the Zika Virus. In her paper on understanding Zika disease evolution and treatment, Moore [10] identifies the value of seeking out different opportunities to address knowledge gaps. Agencies such as the World Health Organisation [11] recognise the value of social media and other interactive technologies to promote Zika knowledge and the global consequences of rapid spread.

Some posts demonstrated knowledge and a wider understanding of issues they knew about, but not through direct experience. For example, the discussion about non-contact rugby tackling was an exploration of the relationship between population health and public health. The non-contact rugby tackle in UK schools was recognized by those students where rugby is a national sport. Sport is an excellent public health promoter because of its global common denominators. The posts show what McPherson et al. [12] identify as the importance of understanding concepts rather just than factual content. Thinking and posting comments about the wider exponents of health which attract media interest focuses on what has been shown to work and when it is threatened. Students recognized the delivery of public health by agencies beyond healthcare provision [13].

The social exchange about concerns which affected them personally such as car parking drew some consternation about issues such as isolation and vulnerability. Here social media was a powerful tool for students to describe what is actually happening in real-time, for example safety, lone working and raised personal awareness. From a teacher-facilitator perspective Ventola's [14] caution on personal-professional boundaries highlights the delicate balance of managing private information on social media. Our project was underpinned with guidance about managing and revealing personal and professional information.

It was inevitable that students would move from direct public health issues to exchanging information about their experiences as learners. One example was some students having to complete a portfolio of practice-based evidence. Whilst online conversations can create misunderstanding and inaccuracy [15], these posts show social media's vicarious protective layer to share, receive and respond to information. Furthermore, the page facilitated opportunities for professional networking about current practice, career choices and future ambitions. The cited paper represents a body of literature on the value of virtual communities for sourcing and sharing professional knowledge [16].

The public health themes covered a diverse range of academic, professional and social topics. In summary, this project reveals not only what students know but how they communicate across a range of different subjects using Facebook. The public health element was a reliable and safe starting point to generate posts and bring this group together. We were also interested in how students collaborate in this context and what kinds of triggers might generate discussion on a casual basis. The analysis therefore offers a small insight into how students engage in conversation and the kinds of 
triggers which pre-empt posts. Free access, ease of use and the ubiquitous presence of social media sites present good conditions to facilitate academic activity on a global scale with different groups of learners.

Research into social media use is an emerging discipline and our paper adds to the growing interest in the creation and exchange of content. One result that we wish to explore further as it affects all of our learning and teaching rests around an understanding that students are not always interested in what faculty find interesting. This raises the issue of how is the curriculum balanced in a meaningful way for students, the academics and the resultant employers. We need to further explore the use of 'Like' and 'Seen By' as the results from the study indicated a substantial use of these metrics by the students over and above the written or uploaded file comments within the topics. Students uploaded images and other media files to the site, in our future work we need to determine a way to be inclusive of materials over and above text.

The research team selected the area of Public Health as this was deemed relevant for the students and was part of their course during the pilot, it was also considered wide ranging enough to allow for diverse discussion amongst the students, however discussions around academic portfolio's and parking at work rated highly on the number of comments they each received. The generation of the topics by the students is another aspect that upon review needs to be reconsidered; in our future work we plan to trial an academic initiated weekly health and social care topic alongside any relevant topic initiated by the students.

\section{Conclusions}

Our collaborative research has demonstrated that within health and social care education social media offers students an opportunity to engage in meaningful exchanges on a global platform in a virtual form. The proof of concept has been positively demonstrated through this pilot, but there are some further unanswered questions which the research team will address through further such studies. This was a positive experience for all the research team and although there were challenges the team are convinced that it was worth the effort and it has pointed us towards our ultimate goal. As communications technology advances across the world, no nurse or nursing student need ever be without recall to a colleague to respond to a request for information for a public health issue he or she is facing that is our goal.

Acknowledgments: The research team would like to acknowledge the assistance of Amanda Howarth and Mark Faulkner from the Department of Nursing and Midwifery, Sheffield Hallam University, as the two independent academics mentioned within the paper.

Author Contributions: P.M.P. conceived the idea. All authors developed and designed the methodology. F.T. and J.J.B. carried out the literature review. Data collection and analyses was carried out by P.M.P., M.L.L.H. and F.T. F.T. reported on the emerging themes, P.M.P. collated the analytics and M.L.L.H. reported on the student experience. All authors were involved in the writing of this article.

Conflicts of Interest: The authors declare no conflict of interest.

\section{References}

1. Todhunter, F.; Hallawell, B.; Pittaway, D. Implementing a virtual exchange project for student nurses in Queensland and Nottingham. Nurs. Educ. Pract. 2013, 13, 371-376. [CrossRef] [PubMed]

2. Gimbel, S.; Kohler, P.; Mitchell, P.; Emami, A. Creating academic structures to promote nursing's role in global health policy. Int. Nurs. Rev. 2017, 64, 117-125. [CrossRef] [PubMed]

3. Webb, O.; Wyness, L.; Cotton, D. Enhancing Access, Retention, Attainment and Progression in Higher Education: A Review of the Literature Showing Demonstrable Impact; Higher Education Academy Publication: York, UK, 2017.

4. Downes, S. What Connectivism Is. 2007. Available online: http://www.downes.ca/post/38653 (accessed on 5 February 2016). 
5. Downes, S. Critical Literacies and Connectivism. 2010. Available online: http://www.downes.ca/post/ 53280 (accessed on 5 July 2016).

6. Siemens, G. Connectivism: A Leaning Theory for the Digital Age. 2004. Available online: http://www. elearnspace.org/Articles/connectivism.htm (accessed on 5 July 2016).

7. Pearce, K. Counting to nowhere: Social media adoption and use as an opportunity for public scholarship and engagement. Soc. Media Soc. 2015. [CrossRef]

8. Li, W.; Cho, E.; Qureshi, A. Epidemiological Assessments of Skin Outcomes in the Nurses' Health Studies. Am. J. Public Health 2016, 106, 1677-1683. [CrossRef] [PubMed]

9. Thornicroft, G.; Deb, T.; Henderson, C. Community mental health care worldwide: Current status and further developments. World Psychiatry 2016, 15, 276-286. [CrossRef] [PubMed]

10. Moore, K. Assessing nurse practitioner knowledge of Zika virus. J. Nurs. Pract. 2016, 12, 697-703. [CrossRef]

11. World Health Organization. WHO Zika App. 2016. Available online: http://www.who.int/riskcommunication/zika-virus/app/en/ (accessed on 5 July 2016).

12. McPherson, C.; Ndumbe-Eyoh, S.; Betker, C.; Oickle, D.; Peroff-Johnston, N. Swimming against the tide: A Canadian qualitative study examing the implementation of a province-wide public health initiative to address health equity. Int. J. Equity Health 2016, 15, 129. [CrossRef] [PubMed]

13. Florini, A.; Nachiappan, K.; Pang, T.; Pilcavage, C. Global health governance: Analysing China, India and Japan as Global Health Aid Donors. Glob. Policy 2012, 3, 336-347. [CrossRef]

14. Ventola, C. Social media and health care professionals: Benefits, risks and best practices. Pharm. Therap. 2014, 39, 491-499.

15. Moorhead, A.; Hazlett, D.; Harrison, L.; Carroll, J.; Irwin, A.; Hoving, C. A New Dimension of Health Care: Systematic Review of the Uses, Benefits, and Limitations of Social Media for Health Communication. J. Med. Intern. Res. 2013, 15. [CrossRef] [PubMed]

16. Rolls, K.; Hansen, M.; Jackson, D.; Elliott, D. How health care professionals use social media to create virtual communities: An integrative review. J. Med. Intern. Res. 2016, 18. [CrossRef] [PubMed]

(C) 2017 by the authors. Licensee MDPI, Basel, Switzerland. This article is an open access article distributed under the terms and conditions of the Creative Commons Attribution (CC BY) license (http:/ / creativecommons.org/licenses/by/4.0/). 